www.nature.com/ja

\title{
New tensidols, JBIR-86 and JBIR-87, isolated from Aspergillus sp. fJ80
}

\author{
Motoki Takagi ${ }^{1}$, Keiichiro Motohashi ${ }^{1}$, Ji-Hwan Hwang ${ }^{1}$, Aya Nagai ${ }^{1}$ and Kazuo Shin-ya ${ }^{2}$
}

The Journal of Antibiotics (2010) 63, 371-373; doi:10.1038/ja.2010.45; published online 12 May 2010

Keywords: Aspergillus; Candida albicans; furopyrrole; miconazole; tensidol

Aspergillus is a member of the phylum Ascomycota. There are over 185 known species of ascomycetes, about 20 of which are known to be harmful to humans and other animals. The Aspergillus species is known to produce more than 1000 secondary metabolites containing bioactive compounds, such as mevinolin, aflatoxin and citrinin. ${ }^{1}$ In a previous study, we reported that a fungus belonging to the Aspergillus species produces a novel secondary metabolite, JBIR-15. ${ }^{2}$ Therefore, in this study, we screened for novel secondary metabolites from cultures of Aspergillus species and succeeded in discovering novel furopyrrole compounds, JBIR-86 (1) and JBIR-87 (2), in addition to the known compounds, tensidols A and B (Figure 1a). In this study, we report the fermentation, isolation and structural determination of $\mathbf{1}$ and 2 , and briefly describe their biological activities.

Aspergillus sp. fJ80 was isolated from a soil sample collected in Akita Prefecture, Japan. The strain was cultivated in $50 \mathrm{ml}$ test tubes containing $15 \mathrm{ml}$ of the seed medium $\left(24 \mathrm{gl}^{-1}\right.$ potato dextrose broth; BD Biosciences, San Jose, CA, USA). The test tubes were shaken on a reciprocal shaker ( 355 r.p.m.) at $27^{\circ} \mathrm{C}$ for 3 days. Aliquots $(5 \mathrm{ml})$ of the seed culture were inoculated into $500 \mathrm{ml}$ Erlenmeyer flasks containing the production medium ( $15 \mathrm{~g}$ brown rice and $45 \mathrm{ml}$ solution containing $0.67 \mathrm{gl}^{-1}$ yeast extract, $0.33 \mathrm{gl}^{-1}$ sodium tartrate dihydrate and $0.33 \mathrm{gl}^{-1} \mathrm{~K}_{2} \mathrm{HPO}_{4}$ ) and incubated in static culture at $27^{\circ} \mathrm{C}$ for 14 days.

The production culture (10 flasks) was extracted with $80 \%$ aqueous $\mathrm{Me}_{2} \mathrm{CO}$ (11) and concentrated in vacuo. The aqueous concentrate $(200 \mathrm{ml})$ was extracted with EtOAc $(200 \mathrm{ml} \times 5)$. After drying over $\mathrm{Na}_{2} \mathrm{SO}_{4}$, the organic layer was evaporated to dryness. The residue $(0.52 \mathrm{~g})$ was subjected to normal-phase, medium-pressure liquid chromatography (Purif-Pack SI-60; Moritex, Tokyo, Japan) and successively eluted with gradient systems of $n$-hexane-EtOAc $(0-30 \%$ EtOAc) and $\mathrm{CHCl}_{3}-\mathrm{MeOH}(0-50 \% \mathrm{MeOH})$. The $1 \% \mathrm{MeOH}$-eluted fraction $(70.0 \mathrm{mg}$ ) was purified by preparative reversed-phase HPLC using an L-column2 ODS column $(20$ i.d. $\times 150 \mathrm{~mm}$; Chemical
Evaluation and Research Institute, Tokyo, Japan) with 55\% $\mathrm{MeOH}-$ $\mathrm{H}_{2} \mathrm{O}$ containing $0.1 \%$ formic acid (flow rate $10 \mathrm{ml} \mathrm{min}^{-1}$ ) to yield 2 $(0.99 \mathrm{mg}$, retention time (Rt) $12.6 \mathrm{~min})$, tensidol B (3.22 mg, Rt $9.1 \mathrm{~min})$ and a crude fraction of $1(7.25 \mathrm{mg}$, Rt $4.3 \mathrm{~min})$. The eluate containing 1 was further purified by preparative reversed-phase HPLC using an L-column2 ODS column (20 i.d. $\times 150 \mathrm{~mm}$ ) with $50 \%$ $\mathrm{MeOH}-\mathrm{H}_{2} \mathrm{O}$ containing $0.1 \%$ formic acid (flow rate $10 \mathrm{ml} \mathrm{min}^{-1}$ ) to yield 1 (1.02 mg, Rt $13.0 \mathrm{~min})$ and tensidol A (3.81 mg, Rt $11.0 \mathrm{~min})$.

Compound $\mathbf{1}$ was isolated as a colorless oil that yielded an $[\mathrm{M}+\mathrm{H}]^{+}$ ion at $\mathrm{m} / z 244.0986$ in the HR-ESI-MS corresponding to a molecular formula of $\mathrm{C}_{14} \mathrm{H}_{12} \mathrm{NO}_{3}$ (calcd for $\mathrm{C}_{14} \mathrm{H}_{13} \mathrm{NO}_{3}, 244.0974$ ). Furthermore, 1 displayed the following UV and IR spectra: UV $\left(\mathrm{CHCl}_{3}\right)$ $\lambda_{\max }(\varepsilon) 241$ (11 750), IR (KBr) $v_{\max } 1670 \mathrm{~cm}^{-1}$. The ${ }^{1} \mathrm{H}$ and ${ }^{13} \mathrm{C}$ NMR spectral data for $\mathbf{1}$ are listed in Table 1 . The structural information on 1 was obtained by a series of 2D NMR analyses such as heteronuclear single-quantum coherence, HMBC and double-quantum filtered (DQF)-COSY spectra (Figure 1b). The spin couplings observed in the DQF-COSY spectrum among aromatic protons $9 / 13-\mathrm{H}\left(\delta_{\mathrm{H}} 7.24\right), 10 / 12-\mathrm{H}\left(\delta_{\mathrm{H}} 7.32\right)$ and $11-\mathrm{H}\left(\delta_{\mathrm{H}} 7.32\right)$ revealed the existence of a phenyl residue. In the $\mathrm{HMBC}$ spectrum, a singlet methylene proton $7-\mathrm{H}\left(\delta_{\mathrm{H}} 3.83\right)$ was ${ }^{1} \mathrm{H}-{ }^{13} \mathrm{C}$ long-range coupled to aromatic methine carbons $\mathrm{C}-9 / 13\left(\delta_{\mathrm{C}} 129.4\right)$. The ${ }^{1} \mathrm{H}-{ }^{13} \mathrm{C}$ long-range couplings from $9 / 13-\mathrm{H}$ to aromatic carbon $\mathrm{C}-11\left(\delta_{\mathrm{C}} 128.0\right)$ and to methylene carbon C-7 $\left(\delta_{\mathrm{C}} 40.0\right)$ established the presence of a benzyl moiety, as shown in Figure 1b. In addition to the resonances ascribed to the benzyl moiety, 1 showed seven additional ${ }^{13} \mathrm{C}$ resonances. Longrange couplings from aromatic protons $2-\mathrm{H}\left(\delta_{\mathrm{H}} 8.43\right)$ and $5-\mathrm{H}\left(\delta_{\mathrm{H}}\right.$ $6.21)$ to each of the aromatic carbons $\mathrm{C}-3\left(\delta_{\mathrm{C}} 163.9\right), \mathrm{C}-3 \mathrm{a}\left(\delta_{\mathrm{C}} 119.8\right)$, $\mathrm{C}-4\left(\delta_{\mathrm{C}} 175.0\right)$ and $\mathrm{C}-6 \mathrm{a}\left(\delta_{\mathrm{C}} 167.6\right)$ were observed. Moreover, the long-range coupling between the methoxyl proton $3-\mathrm{OMe}\left(\delta_{\mathrm{H}} 3.87\right)$ and $\mathrm{C}-3$ revealed that the methoxyl group is substituted at the C-3 position. A comparison of the ${ }^{13} \mathrm{C}$ chemical shifts with those of

${ }^{1}$ Biomedicinal Information Research Center, Japan Biological Informatics Consortium, Tokyo, Japan and 2Biomedicinal Information Research Center, National Institute of Advanced Industrial Science and Technology, Tokyo, Japan

Correspondence: Dr M Takagi, Biomedicinal Information Research Center, Japan Biological Informatics Consortium, 2-4-7 Aomi, Koto-ku, Tokyo 135-0064, Japan.

E-mail: motoki-takagi@aist.go.jp or Dr K Shin-ya, Biomedicinal Information Research Center, National Institute of Advanced Industrial Science and Technology, 2-4-7 Aomi, Koto-ku, Tokyo 135-0064, Japan.

E-mail: k-shinya@aist.go.jp

Received 6 March 2010; revised 15 April 2010; accepted 16 April 2010; published online 12 May 2010 
a<smiles>Oc1coc2c1c(O)cn2Cc1ccccc1</smiles>

$\mathbf{R}_{\mathbf{1}}=\mathrm{CH}_{\mathbf{3}} \quad$ JBIR-86 (1) $\mathbf{R}_{\mathbf{1}}=\mathbf{H} \quad$ Tensidol A

b

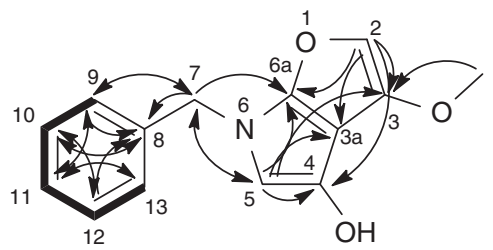

c

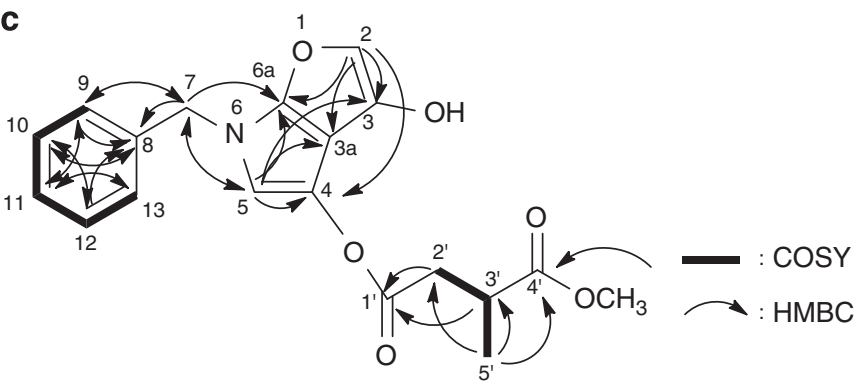<smiles>[R6]=P</smiles>

d

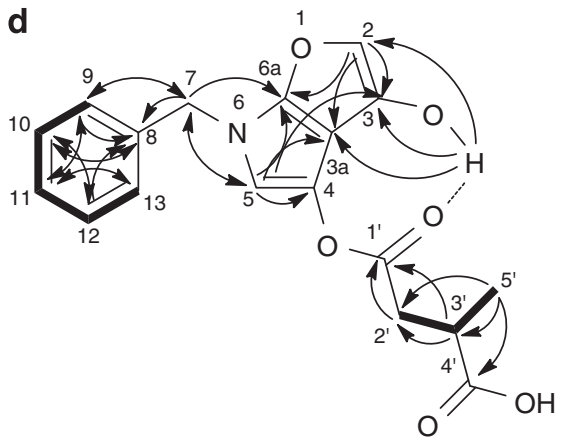

Figure 1 (a) Structures of tensidols, JBIR-86 (1) and JBIR-87 (2). (b) Key correlations in DQF-COSY (bold lines) and HMBC (arrows) spectra of 1. (c) Key correlations in DQF-COSY (bold lines) and HMBC (arrows) spectra of 2. (d) Key correlations in DQF-COSY (bold lines) and HMBC (arrows) spectra of tensidol B.

Table $1{ }^{1} \mathrm{H}$ and ${ }^{13} \mathrm{C}$ NMR spectral data for JBIR-86 (1), JBIR-87 (2) and tensidol B

\begin{tabular}{|c|c|c|c|c|c|c|}
\hline \multirow[b]{2}{*}{ Position } & \multicolumn{2}{|c|}{1} & \multicolumn{2}{|r|}{2} & \multicolumn{2}{|c|}{ Tensidol B } \\
\hline & ${ }^{13} \mathrm{C}$ & ${ }^{1} H(J$ in $H z)$ & ${ }^{13} \mathrm{C}$ & ${ }^{1} H(J$ in $H z)$ & ${ }^{13} \mathrm{C}$ & ${ }^{1} H(J$ in $\mathrm{Hz})$ \\
\hline 3 & $163.9^{a}$ & & $162.7^{\mathrm{a}}$ & & 161.5 & \\
\hline $3 a$ & 119.8 & & 119.5 & & 118.8 & \\
\hline 4 & $175.0^{\mathrm{a}}$ & & $179.7^{a}$ & & 178.0 & \\
\hline 7 & 40.0 & $3.83, \mathrm{~s}$ & 40.0 & $4.06, \mathrm{~s}$ & 39.8 & $3.88, \mathrm{~s}$ \\
\hline 8 & 134.1 & & 135.9 & & 133.7 & \\
\hline 9 & 129.4 & $7.24, \mathrm{~m}$ & 130.3 & 7.34, m & 130.3 & 7.22, m \\
\hline 10 & 129.3 & $7.32, \mathrm{~m}$ & 130.0 & $7.36, \mathrm{~m}$ & 129.4 & $7.36, \mathrm{~m}$ \\
\hline 11 & 128.0 & $7.32, \mathrm{~m}$ & 128.7 & 7.32, m & 128.7 & 7.30, m \\
\hline 12 & 129.3 & $7.32, \mathrm{~m}$ & 130.0 & $7.36, \mathrm{~m}$ & 129.4 & $7.34, \mathrm{~m}$ \\
\hline $3^{\prime}$ & & & 36.3 & $2.98, \mathrm{~m}$ & 35.1 & $3.02, \mathrm{~m}$ \\
\hline $4^{\prime}$ & & & 177.8 & & 180.8 & \\
\hline $5^{\prime}$ & & & 17.4 & $1.22, \mathrm{~d}(7.2)$ & 17.2 & $1.26, d(7.2)$ \\
\hline $3-\mathrm{OCH}_{3}$ & 52.8 & $3.87, \mathrm{~s}$ & & & & \\
\hline $4^{\prime}-\mathrm{OCH}_{3}$ & & & 52.4 & $3.66, \mathrm{~s}$ & & \\
\hline $3-\mathrm{OH}$ & & & & 11.71 & & 11.72 \\
\hline
\end{tabular}

${ }^{13} \mathrm{C}(150 \mathrm{MHz})$ and ${ }^{1} \mathrm{H}(600 \mathrm{MHz}) \mathrm{NMR}$ spectra were recorded using NMR System $600 \mathrm{NB} \mathrm{CL}$ (Varian, Palo Alto, CA, USA) in $\mathrm{CDCl}_{3}$ with the residual solvent peak being used as an internal standard $\left(\delta_{\mathrm{C}} 77.0, \delta_{\mathrm{H}} 7.24\right.$ p.p.m.). aThese assignments are exchangeable. 
tensidol A suggested the existence of a 4-methoxy-6H-furo[2,3-b]pyrrol3-ol moiety ${ }^{3}$ (Figure 1b). Finally, the ${ }^{1} \mathrm{H}-{ }^{13} \mathrm{C}$ long-range couplings from 7-H to C-5 and C-6a and from 5-H to C-7 established a relation between these partial structures. Although four-bond HMBC correlations from $\mathrm{H}-2$ to $\mathrm{C}-4$ and from $\mathrm{H}-5$ to $\mathrm{C}-3$ were observed, and the ${ }^{13} \mathrm{C}$ chemical shifts were identical to the tensidol A chemical shifts, we could not determine the exact assignment of the C-3 and C-4 signals.

Compound 2 was obtained as a colorless oil $\left([\alpha]_{\mathrm{D}}+6.0, c 0.1\right.$, $\mathrm{MeOH})$, and it displayed a UV spectrum $\left(\lambda_{\max }(\varepsilon) 239\right.$ (14050), in $\left.\mathrm{CHCl}_{3}\right)$ and an IR spectrum $\left(\mathrm{KBr}, v_{\max } 1730\right.$ and $\left.1670 \mathrm{~cm}^{-1}\right)$. The molecular formula of 2 was established as $\mathrm{C}_{19} \mathrm{H}_{18} \mathrm{NO}_{6}$ by HR-ESI-MS $\left(m / z 358.1286[\mathrm{M}+\mathrm{H}]^{+}\right.$, calcd for $\left.\mathrm{C}_{19} \mathrm{H}_{19} \mathrm{NO}_{6}, 358.1291\right)$. The NMR data were similar to those of 1 except for the appearance of two carbonyl carbons $\mathrm{C}-1^{\prime}\left(\delta_{\mathrm{C}} 174.4\right)$ and $\mathrm{C}-4^{\prime}\left(\delta_{\mathrm{C}} 177.8\right)$, a methine carbon $\mathrm{C}-3^{\prime}\left(\delta_{\mathrm{C}} 36.3\right)$, a methylene carbon C-2' $\left(\delta_{\mathrm{C}} 42.6\right)$ and a methyl carbon $\mathrm{C}-5^{\prime}\left(\delta_{\mathrm{C}} 17.4\right)$, as listed in Table 1 . The sequence from doublet methyl protons $\mathrm{H}-5^{\prime}\left(\delta_{\mathrm{H}} 1.22\right)$ to methylene protons $\mathrm{H}-2^{\prime}\left(\delta_{\mathrm{H}} 2.90\right.$, 3.16) through a methine proton $3^{\prime}-\mathrm{H}\left(\delta_{\mathrm{H}} 2.98\right)$ was observed in the DQF-COSY spectrum. The long-range couplings from methoxyl protons $4^{\prime}-\mathrm{OMe}\left(\delta_{\mathrm{H}} 3.66\right)$ to $\mathrm{C}-4^{\prime}$; from $5^{\prime}-\mathrm{H}$ to $\mathrm{C}-2^{\prime}, \mathrm{C}-3^{\prime}$ and $\mathrm{C}-4^{\prime}$; and from $2^{\prime}-\mathrm{H}$ and $3^{\prime}-\mathrm{H}$ to $\mathrm{C}-1^{\prime}$ established the presence of a 4-methoxy-3-methyl-4-oxobutanoate moiety, as shown in Figure 1c. Because the long-range couplings from $3-\mathrm{OH}\left(\delta_{\mathrm{H}} 11.71\right)$ were not the same as those observed in $\mathbf{1}$, we could not determine the substituted position of the side-chain moiety. To determine the assignment of C-3 and C-4, which would establish the substituted positions of the methyl residue and the side-chain moiety in $\mathbf{1}$ and 2, respectively, detailed NMR analyses of tensidol B isolated from Aspergillus sp. fj80 were carried out (Figure 1d). Using the analysis results, we could confirm that the long-range couplings from a hydrogen-bonded phenolic hydroxy proton $3-\mathrm{OH}\left(\delta_{\mathrm{H}} 11.72\right)$ to $\mathrm{C}-2\left(\delta_{\mathrm{C}} 163.4\right), \mathrm{C}-3\left(\delta_{\mathrm{C}} 161.5\right)$ and $\mathrm{C}-3 \mathrm{a}\left(\delta_{\mathrm{C}} 118.8\right)$ established the exact assignment of all the signals of tensidol $\mathrm{B}$ and $3-\mathrm{OH}$ was found to be substituted at the $\mathrm{C}-3$ position. Taking into consideration the ${ }^{13} \mathrm{C}$ chemical shifts at $\mathrm{C}-3$ and C-4 in both 1 and 2, we conclude that the methyl residue and 4methoxy-3-methyl-4-oxobutanoate moiety of $\mathbf{1}$ and $\mathbf{2}$ are substituted at the C-3 and C-4 positions, respectively. Note that the assignment of the ${ }^{1} \mathrm{H}$ and ${ }^{13} \mathrm{C}$ NMR signals published by Fukuda et al. ${ }^{3}$ should be corrected as per the results of this study. The identical ${ }^{1} J_{\mathrm{C}-\mathrm{H}}$ values at C-2 and C-5 in tensidol B, 1 and $2\left({ }^{1} J_{2 \mathrm{C}-2 \mathrm{H}}\right.$ : tensidol B $200.6 \mathrm{~Hz}$, $1197.4 \mathrm{~Hz}, 2198.0 \mathrm{~Hz} ;{ }^{1} J_{5 \mathrm{C}-5 \mathrm{H}}$ : tensidol B $167.5 \mathrm{~Hz}, 1165.4 \mathrm{~Hz}, 2$ $168.0 \mathrm{~Hz}$ ) provided further evidence in support of the proposed structures of $\mathbf{1}$ and 2. Thus, $\mathbf{1}$ and $\mathbf{2}$ were established as 3-O-methyl tensidol A and 4'-O-methyl tensidol B, respectively.

Because it has been reported that tensidols $\mathrm{A}$ and $\mathrm{B}$ potentiate miconazole activity against Candida albicans, ${ }^{3}$ we tested the miconazole-potentiating activities of $\mathbf{1}$ and $\mathbf{2}$ using the previously reported
Table 2 Miconazole-potentiating activity of tensidols, JBIR-86 (1) and JBIR-87 (2)

\begin{tabular}{|c|c|c|c|}
\hline \multirow[b]{2}{*}{ Compounds } & \multirow{2}{*}{$\begin{array}{c}\text { Concentration } \\
\mu g \text { per disk }(6 \mathrm{~mm})\end{array}$} & \multicolumn{2}{|c|}{ Inhibition zone (mm) } \\
\hline & & Plate $A$ & Plate B \\
\hline \multirow[t]{3}{*}{ Tensidol A } & 50 & - & 21 \\
\hline & 25 & - & 14 \\
\hline & 10 & - & 8 \\
\hline \multirow[t]{3}{*}{1} & 50 & - & 11 \\
\hline & 25 & - & 7 \\
\hline & 10 & - & - \\
\hline \multirow[t]{3}{*}{ Tensidol B } & 50 & - & 14 \\
\hline & 25 & - & 9 \\
\hline & 10 & - & - \\
\hline \multirow[t]{3}{*}{2} & 50 & - & 16 \\
\hline & 25 & - & 10 \\
\hline & 10 & - & - \\
\hline
\end{tabular}

Plate $A$ is a GY agar plate containing a $0.1 \%$ aliquot of $C$. albicans NBRC 1594 culture, and plate $B$ is a GY agar plate containing $C$. albicans and $0.06 \mu \mathrm{m}$ miconazole.

paper disk method. ${ }^{3,4}$ As in the case of the tensidols, 1 and 2 did not show an inhibition zone against C. albicans at $50 \mu \mathrm{g}$ per disk (plate A) and exhibited miconazole-potentiating activity in a dose-dependent manner on plate B (plate A containing $0.06 \mu \mathrm{M}$ miconazole), as listed in Table 2. However, the activity of $\mathbf{1}$ was weaker than that of tensidol A. In addition, the cytotoxic activity of $\mathbf{1}$ and $\mathbf{2}$ against several cancer cell lines was tested by the WST-8 (2-(2-methoxy-4-nitrophenyl)-3(4-nitrophenyl)-5-(2,4-disulfophenyl)-2H-tetrazolium, monosodium salt) colorimetric assay (Cell Counting Kit; Dojindo, Kumamoto, Japan). However, 1 and $\mathbf{2}$ showed no cytotoxicity even at a concentration of $50 \mu \mathrm{g} \mathrm{ml}^{-1}$ for $48 \mathrm{~h}$.

\section{ACKNOWLEDGEMENTS}

This work was supported by a grant from the New Energy and Industrial Technology Department Organization (NEDO) of Japan.

1 Bérdy, J. Bioactive microbial metabolites. J. Antibiot. (Tokyo) 58, 1-26 (2005).

2 Motohashi, K., Inaba, S., Takagi, M. \& Shin-ya, K. JBIR-15, a new aspochracin derivative, isolated from a sponge-derived fungus, Aspergillus sclerotiorum Huber Sp080903f04. Biosci. Biotechnol. Biochem. 73, 1898-1900 (2009).

3 Fukuda, T. et al. Tensidols, new potentiators of antifungal miconazole activity, produced by Aspergillus niger FKI-2342. J. Antibiot. 59, 480-485 (2006).

4 Arai, M. et al. Funicone-related compounds, potentiators of antifungal miconazole activity, produced by Talaromycesflavus FKI-0076. J. Antibiot. (Tokyo) 55, 172-180 (2002) 